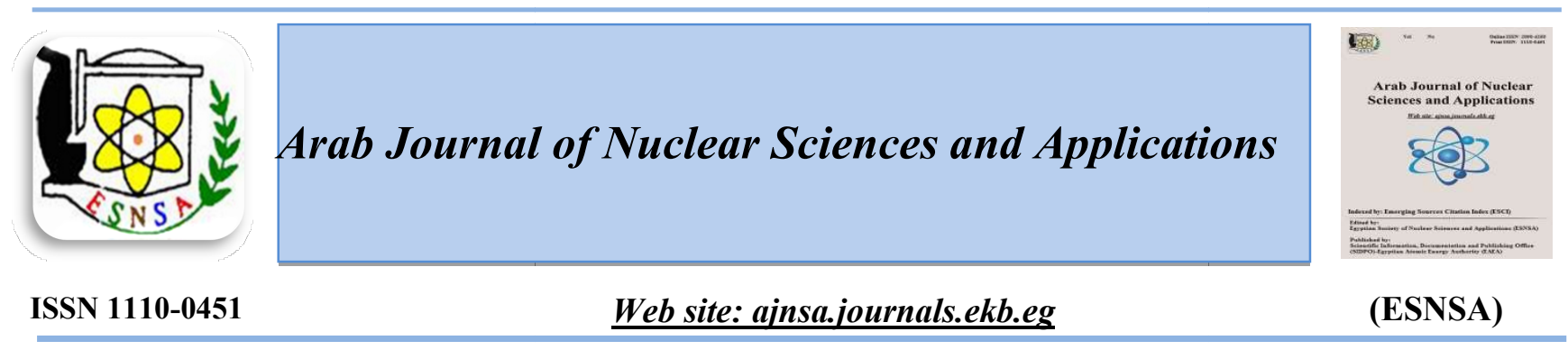

\title{
An Efficient Computational Approach for Phonocardiogram Signals Analysis and Normal/Abnormal Heart Sounds Diagnosis
}

\author{
El-Sayed A. El-Dahshan ${ }^{1}$, Mohammed Nabih- Ali ${ }^{2}$ and Ashraf S. Yahia ${ }^{1}$ \\ ${ }^{(1)}$ physics Department, Faculty of Science, Ain Shams University \\ (2) Egyptian E-Learning University (EELU)
}

Received $14^{\text {th }}$ Dec. 2019 Accepted $23^{\text {rd }}$ June2020

\section{Introduction}

Cardiovascular diseases (CVDs) are abnormal functioning of the heart or blood vessels. CVDs are considered the world's largest cause of death [1]. Nearly 17.7 million individuals died as a result of CVDs in 2015; representing about 31 percent of deaths over the world [1, 2]. Detection of cardiac diseases in an early stage is very important and represents a motivation for further studies.

The auscultation defined by R. Laennec in 1816 [3] as listening and interpretation of cardiac sounds can provide evidence to the diagnosis of many cardiac abnormalities [4]. Physicians use the stethoscope to listen to the heart valves functions, study the physical characteristics of cardiac sounds and make an accurate diagnosis accurately. Unfortunately, this mechanical tool is highly dependent on the clinicians experience, it cannot store or replay sounds, cannot offer a graphical display, and certainly cannot process the acoustic biomedical signal [5].

For these shortcomings, an alternative method has emerged called phonocardiogram (PCG). PCG is a recording of cardiac sounds that carries the physical characteristics and pathological information about the function of human heart. PCG can be stored for time/frequency (T-F) analysis [6-7]. The mechanism of cardiac sounds is very complex. Generally, cardiac sounds include:

- Sounds: vibrations generated by valves closure and by the tensing of the cardiac muscle.

- Murmurs: extra sound generated due to the instability in the blood flow from narrow cardiac valves.

In normal PCG acoustic signals, two main audible components are provided: (S1 "first sound" and S2 "second sound") with time duration of $150 \mathrm{~ms}$ and $120 \mathrm{~ms}$ approximately and frequency from 20 to

Corresponding author:e eldahshan@yahoo.com

DOI: 10.21608 /ajnsa.2020.20968.1312

(C)Scientific Information, Documentation and Publishing Office (SIDPO)-EAEA 
$150 \mathrm{~Hz}$ [8]. Two extra low frequency inaudible cardiac sound components called (S3 and S4) may be heard.

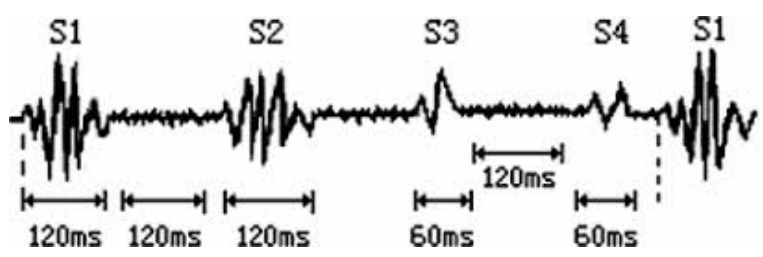

Fig. (1): PCG acoustic signal with the main two components ( $\mathrm{S} 1$ and $\mathrm{S} 2)$ and the extra component ( $\mathrm{S3}$ and S4)

Distinguishing accurately between acoustic signals PCG components of normal cardiac sound and diagnosis of cardiac diseases requires a lot of training and experience to make a correct diagnosis decision. Automatic cardiac sound interpretation and cardiac diseases analysis utilizing machine learning (ML) can address this issue and help the clinician in recognizing abnormality that cannot be identified manually.

Recent researches and studies in the field of artificial intelligence (AI) have led to the importance of expert systems and intelligent approaches for general and special medical applications. Building accurate and fast intelligent systems for automatic detection of abnormalities in PCG acoustic signals is crucial for clinicians in the diagnosis of different cardiac diseases [9]. In the previous couple of decades, several intelligent approaches for PCG acoustic signal analysis classifications have been developed to increase the performance of the cardiac diseases' diagnosis process. Each useful practical achievement of the PCG diagnosis system demands an efficient heart signal processing scheme that can extract features and perform classification $[10,12]$.These approaches include two main phases to implement in the diagnosis of cardiac diseases process: The first is feature extraction and the second is classification. Several methods have been reported for feature extractions; which include time, frequency, T-F domains and wavelet transform (WT) based features [13]. However, WT-based analysis is highly effective, because it deals with the biomedical signal of non-stationary behavior as PCG acoustic signals better than other methods. Also, several different techniques have been reported in the literature which utilized different types of classification techniques (ML techniques) such as artificial neural networks (ANN), support vector machine (SVM), and other techniques for the diagnosis of cardiac diseases [13].Thus, in the next section, a review will be presented for the most important works related to the automatic classification of pathological and standard heart. Moreover, based on the literature of the classification for heart states presented in Section 2 , it can be stated that this point still needs further examination to improve the accuracy of clinician's decision for cardiac diseases diagnosis. Therefore, the purpose of this study is to extract PCG effective audio features based on discrete wavelet transform (DWT) for the characterization of the standard and pathological cardiac acoustic signals based on ANN. The PCGPASACAL CHSC 2011 dataset is [14] used for the building up and validation of the proposed approach.

The rest of this article includes four sections: Section (2) reviews the most related and recent techniques used in acoustic signals PCG analysis. Section (3) presents the materials and methodology used in this research. Section (4) presents the experimental results with discussion and finally the conclusion

\section{Related works}

Much research has been conducted concerning the investigation of the PCG acoustic signals for automated recognition of different heart variations and abnormalities. Typically, analysis of acoustic signals PCG is based on four stages: signal denoising, segmentation, feature extraction and classification. This section covers the most recent techniques for each stage for detecting abnormalities in PCG acoustic signals. The number of the recordings and signal frequency range are the most important parameters that restrict the available databases. Several heart diagnosis systems used the PASCALCHSC [14]. The PASCAL CHSC includes a real cardiac sound from both normal and pathological patients.

- Denoising PCG acoustic signals from noises is a primary stage in cardiac sound analysis systems. Noise can distort the characteristics of cardiac acoustic signals and decrease the decision accuracy. Several approaches are utilized to eliminate and reduce the noise; including DWT, continuous wavelet transform (CWT), low (L)and high $(\mathrm{H})$-pass filters [15-22].

- Segmentation of PCG acoustic signals into cycles and then separating PCG acoustic signals into 
systolic"S1" and diastolic "S2" phases. Several methods have been presented for this stage, such as power spectral density (PSD), normalized average Shannon energy (NASE), WT, homomorphic filtering, etc. [21, 23-25].

- Feature extraction is the process concerned with extracting the features that represent the main events in PCG acoustic signals. These features are the fundamental basis for classification task in biomedical signal. For example, features of PCG acoustic signal descriptors (amplitude, voltage, phase, frequency, etc.). Features vector in the state of art can be organized in two classes. The first class refers to medical knowledge about specific diseases effect on cardiac sound. The second class of features is T-F analysis of signal which is suitable for PCG acoustic signals since they are biomedical of non stationary nature signals. This means that their frequency components vary with time. There are many features extraction algorithms available; such as linear frequency band cepstral, the Melfrequency cepstral coefficients, short time Fourier transform, pseudo-affine Winger-Ville distribution (PAWVD) and CWT and DWT [2629].

- PCG acoustic signals classification which is the main goal of this research was studied. A part of these studies deals with classification between standard and abnormal PCG acoustic signals, or with classification between different types of murmurs [30 - 33]. It should be mentioned that most of researches concerned with PCG acoustic signals classification use the ANN with different algorithms such as: ANN back-propagation (BP) algorithm and Kohonen's self-organizing feature map $[25,34]$. Other studies use other classifiers in classification process such as: K-Nearest Neighbor (KNN) classifier, SVM, adaptive-ne Murmursuro fuzzy inference system (ANFIS) and Hidden Markov model (HMM) [32-35].

Among the techniques that had been used for heart abnormalities detection based on PCG acoustic signals, it could be concluded that WT is the most commonly used technique for feature extraction and the efficient classifier is the ANN. It is clear that PCG acoustic signals analysis is still under research and study aiming to achieve the optimal techniques. For this reason, this research aims at proposing an intelligent approach for analysis and classification of PCG acoustic signals to support clinicians in heart abnormality detection. The present investigation deals with DWT for feature extraction and ANN for classification of PCG acoustic signals abnormality.

\section{Materials and Methodology}

In this section the details of the materials and methodology used during this research including the dataset description, experimental specification, DWT, and ANN are described. The schematic drawing of the proposed intelligent approach is shown in Fig.(2). It can be found that the whole methodology included four essential parts namely, data collections, signal preprocessing (signal denoising, signal scalogram and segmentation), feature extraction and classification.

\section{Datasets}

The collection of dataset is one of the most important tasks of signal processing. An online available dataset called PASCAL CHSC 2011 heart sound dataset is used in the present work [14]. Data has been collected from two sources: dataset (A) from the iStethoscope Pro iPhone (contains 176 records), and dataset (B) (contains 656 records) using the digital stethoscope (from a clinical examination).Only a section of the database (A) composed of 170 signals was used (because noise in Dataset (A) recordings is less than Dataset (B) recordings). The acoustic audio files lengths vary between 1-30 seconds. Generally, most of information in PCG acoustic signals is included in the low frequency segments, having little noise in the upper frequencies. So, it is common to use an L-pass filter at $195 \mathrm{~Hz}$. The database (PASCAL CHSC 2011) has two categories:

- Normal category: in this category healthy cardiac sounds were recorded and it may be noisy in the last second of recordings when the instrument was moved from the body. They may also have in frequent random noise corresponding to lung movement or microphone brushing touching skin.

- Pathological category: Contains heart murmur sounds as if it is a "whooshing, noisy, rumbling, or fluid turbulent" noise. 


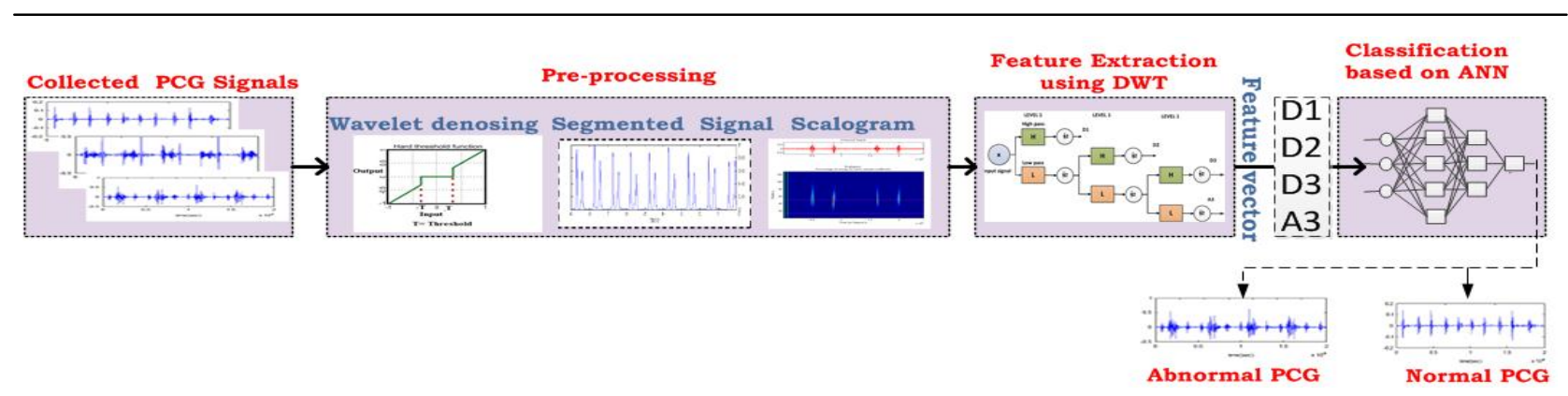

Fig. (2): Sketch of the functional flow of the proposed intelligent approach

\section{Wavelet transforms (WT)}

The WT is an effective mathematical tool for signal processing (e.g. signal denoising and feature extraction) and it has been utilized to extract the wavelet coefficient from signals. Wavelets are mathematical functions which satisfy the condition "zero-mean" i.e. localized function. The wavelets are a set of scaled (dilated and compressed) and translated $\Psi_{a, b}(t)$ of some chosen mother wavelet function $\Psi((t)$. The mother wavelet is defined as follows:

$$
\Psi_{a, b}(t)=\frac{1}{\sqrt{|\mathrm{a}|}} \Psi((t-b) / a)
$$

The CWT of a signal $x(t)$ (in our case PCG acoustic signal), square-integrable function relative to a real-valued wavelet, $\Psi(\mathrm{t})$ is defined as [36]:

$$
W_{\psi}(a, b)=\int_{-\infty}^{\infty} x(t) * \Psi_{a, b}(t) d x
$$

and the wavelet $\Psi_{\mathrm{a}, \mathrm{b}}$ is computed from the mother wavelet $\Psi$ by translation and dilation (scaling); a is choice of suitable(appreciate) wavelet function and the order of the decomposition level is important in the analysis of PCG acoustic signal feature elicitation using the DWT.

\section{Signal preprocessing}

This is considered the first stage of acoustic signals PCG processing, where it essentially acts to eliminate noises and artifacts from input PCG acoustic signals using DWT. For preprocessing of the cardiac acoustic PCG signal, noise elimination involves different stratifications for various noise sources. This stage is has been accomplished before extracting the features which leads to increasing the system efficiency.
The dilation factor and $\mathrm{b}$ is the translation parameter (both being real positive numbers) [36]. The dilation function a is chosen as two of $b$ ( $\left.a=2^{b}, a \in \mathfrak{R}_{+}, b \in \mathfrak{R}\right)$ to give the DWT.

The mother wavelet in this case is defined as $\Psi_{j, k}(t)=2^{\mathrm{j} / 2} \Psi\left(\left(2^{j} t-k\right)\right)$, where $\mathrm{j}$ and $\mathrm{k}$ are integer dilation (scale) and translation (position) respectively.

DWT is a linear transformation operating on a feature vector with integer length and produces new vector of the same length called wavelet coefficients vector. DWT is represented using a digital filtering technique "sub-sampling coding technique" to extract the wavelet coefficients based on a cascade of L-and H-pass filters. Further details are discussed in previous studies [26, 36, 37]".In this work, DWT derived features extracted are considered using the Daubechies wavelet (Db wavelet). The extracted feature vector contains the wavelet coefficients that were calculated in subbands at different scales. The

\section{Signal Denoising}

In this stage the different noise structures are eliminated using $\mathrm{Db}$ wavelet of tenth order with $4^{\text {th }}$ level of decomposition. Denoising procedures of the PCG acoustic signal consist of 3 steps [38, 39]. The first step is adding Gaussian white noise (GWN) which is a random signal containing all possible frequencies in equal weight. In this research, GWN is added to the PCG acoustic signals with signal to noise ratio (SNR) equals 5, so the output signal can be formulated as: $y(t)=x(t)+n(t)$, where $\mathrm{y}(\mathrm{t})$ is the out output signal, $x(t)$ is the original signal and $n(t)$ is the noise signal. The next step is PCG acoustic signals decomposition into approximate and details coefficients using $\mathrm{Db}$ wavelet family of tenth order with $4^{\text {th }}$ level of decomposition. Signal decomposition details coefficients were then

Arab J. Nucl.Sci. \&Applic.Vol. 52, No.3 (2020) 
threshold from first to fourth level using hard thresholding technique with "Rigrsure" thresholding rule [40]. In this study, we used the hard thresholding:

$\bar{d}_{j, k}($ H a rd threshold $)=\left\{\begin{array}{ll}d_{j, k} & \left|d_{j, k>T}\right|, \\ 0 & \left|d_{j, k \leq T}\right|\end{array}\right.$,

where $\mathrm{T}$ is the candidate thresholding and $d_{j, k}$ is detail coefficients of level $\mathrm{j}$. $\mathrm{T}$ is selected as the universal threshold. $T=\sigma \sqrt{2 \ln N}$

Where, $\sigma=$ median $\left(\left|d_{1, k}\right| / 0.6745\right)$ is the noise level, $d_{1, k}$ is the wavelet coefficient, and $\mathrm{N}$ is the length of the signal. Finally, the signals were constructed using inverse DWT (IDWT), based on approximate on coefficients of fourth level and denoised detail coefficients from first level to fourth level .Fig. 3 shows the denoised signal and the effect of wavelet on denoising acoustic signals PCG using fourth level of decomposition.

\section{Segmentation}

PCG acoustic signals segmentation is the $2^{\text {nd }}$ step of signal preprocessing aiming at separating the main events in the cardiac cycle such as (S1), (S2) and murmurs. The developed approach is based on the envelope calculated utilizing the NASE to reduce noise effect at low levels. Initially, the original signal $\mathrm{x}(\mathrm{t})$ is decimated utilizing the cut- off frequency $882 \mathrm{~Hz}$ of a type I eighth order Chebyshev filter. Next, PCG acoustic signals normalization is conducted according to: $x(t)_{\text {norm }}=\left[\frac{x(t)}{\max |x(t)|}\right]^{2}, \quad$ After that, the normalized decimated signal envelope was calculated using Shannon energy (SE) [30, 41]. Finally, the average Shannon energy (ASE) is calculated continuously over 0.02 second segments through the signal with 0.01 second segment overlapping. ASE is calculated from (Eq. 3):

$E_{S}(t)=\frac{-1}{N} \sum_{i=1}^{N} x_{\text {norm }}^{2}(i) \cdot \log x_{\text {norm }}^{2}(i)$

Where Xnorm the decimated and normalized sample is signal and $\mathrm{N}$ is the signal length. Finally, the time-dependent NASE is computed from the following equation (Eq. 4):

$$
p_{a}(t)=\frac{E_{S}(t)-M\left(E_{s}(t)\right)}{S\left(E_{S}(t)\right)}
$$

Where $\mathrm{S}\left(\mathrm{E}_{\mathrm{s}}(\mathrm{t})\right), \mathrm{M}\left(\mathrm{E}_{\mathrm{s}}(\mathrm{t})\right)$ are the standard deviation and mean of ASE. Fig. 4 a and $b$ depicts a plot of PCG acoustic signal envelope using the proposed segmentation algorithm.
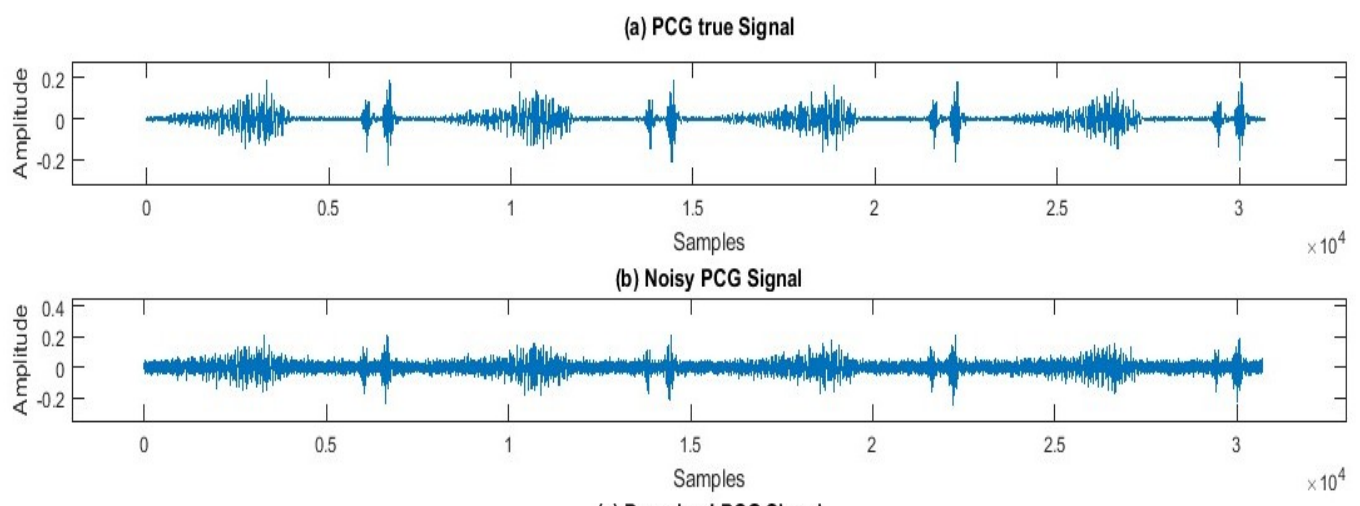

(c) De-noised PCG Signal

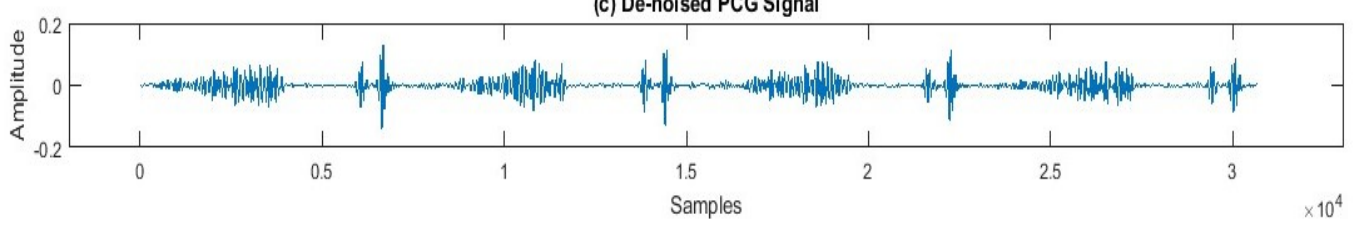

Fig. (3): Denoising of PCG acoustic signal using Db10 wavelet with fourth level and hard thresholding 

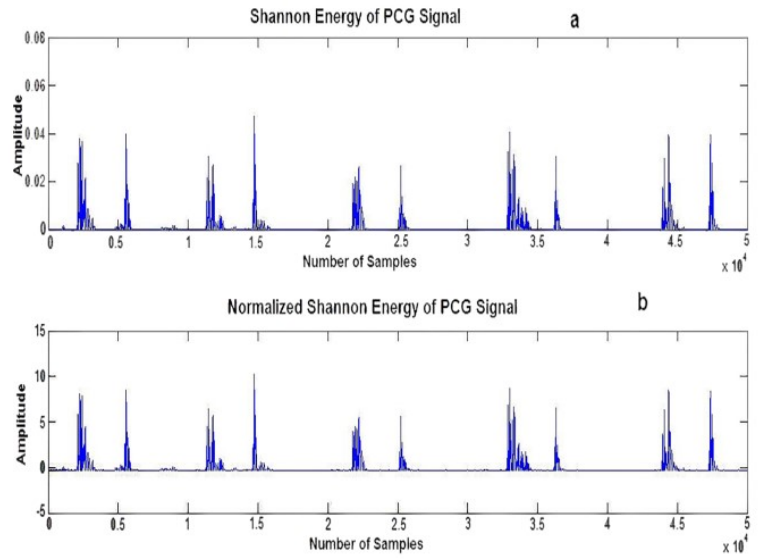

Fig. 4(a) Segmented PCG acoustic signal using Shannon energy (b) Normalized Shannon energy for PCG signals

\section{PCG acoustic signals scalogram}

We used the scalogram to show how the energy strength of the signal changes in time-scale (T-S) plane (scalogram is analogous to the spectrogram in T-F analysis). Signal scalogram is a three dimension T-S representation that plots the spectral components variation on vertical axis with respect to time with horizontal axis. The third dimension represents the frequency (scale) amplitude represented by color intensity of each point in the signal [42].After obtaining the T-S signal representation; its energy must be computed, to get smoother energy estimation. The scalogram provides an additional understanding into time dependent varying of murmur frequency utilizing WT to acquire time changing scalogram maps.
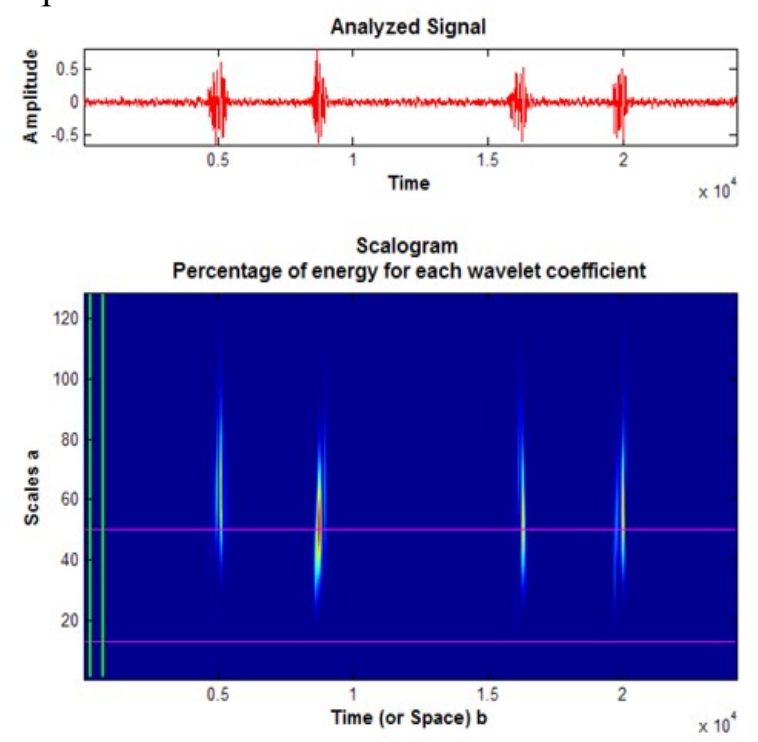

Scalogram, thus, provides temporal localization of the energy foci, which is expected to belong to the fundamental components of the signal. Thus, an envelope of the PCG acoustic signal can be obtained with more accuracy. Representing PCG acoustic signals in the time domain is very important, but it cannot give a clear insight into the spectral components. Contrary to that, frequency domain can provide more details and insight into the spectral components of cardiac cycle events. So, joining T-F domains provides simultaneous 3D analysis of PCG acoustic signals in both domains. Figs. (5 and 6) show the spectral components of normal and pathological PCG acoustic signals obtained using DWT. The color-coded plots reveal that there are variations in the spectral components due to the nature of the cardiac PCG signals. The most effective frequencies, those contribute the total energy can be detected based on the scalogram representative of the signal. The investigation of the signal based on WT gives a value tool in the analysis of signals. It provides accurate location in time of high frequency components. The choice of a mother wavelet of high relation with the signal under examination gives a more exact T-F investigation.
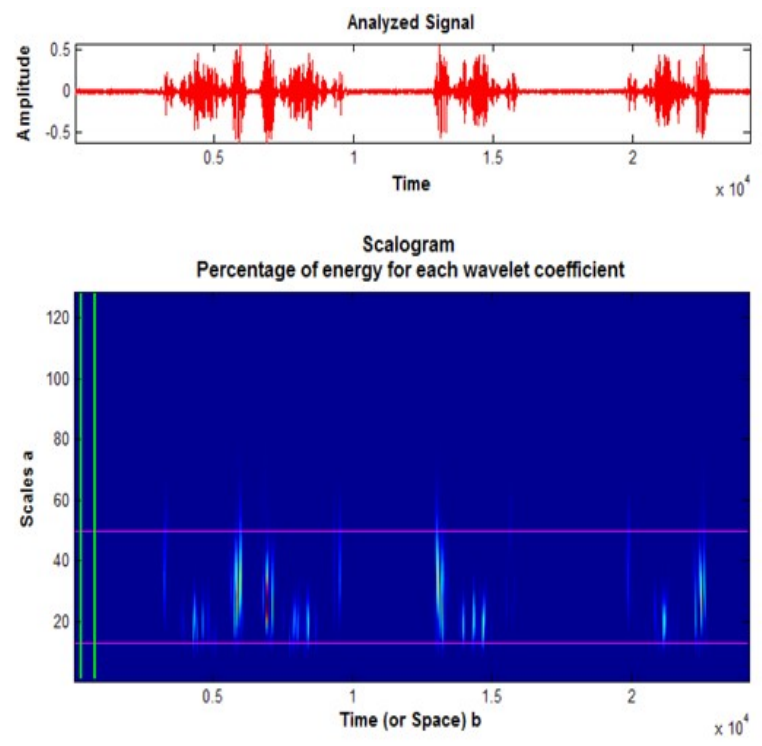

Arab J. Nucl.Sci. \&Applic.Vol. 52, No.3 (2020) 
Fig. (5): Spectral information of normal PCG acoustic signal using WT (a) High Resolution 2D spectrographic image of Normal PCG signal (b) High Resolution 2D spectrographic image of abnormal PCG signal
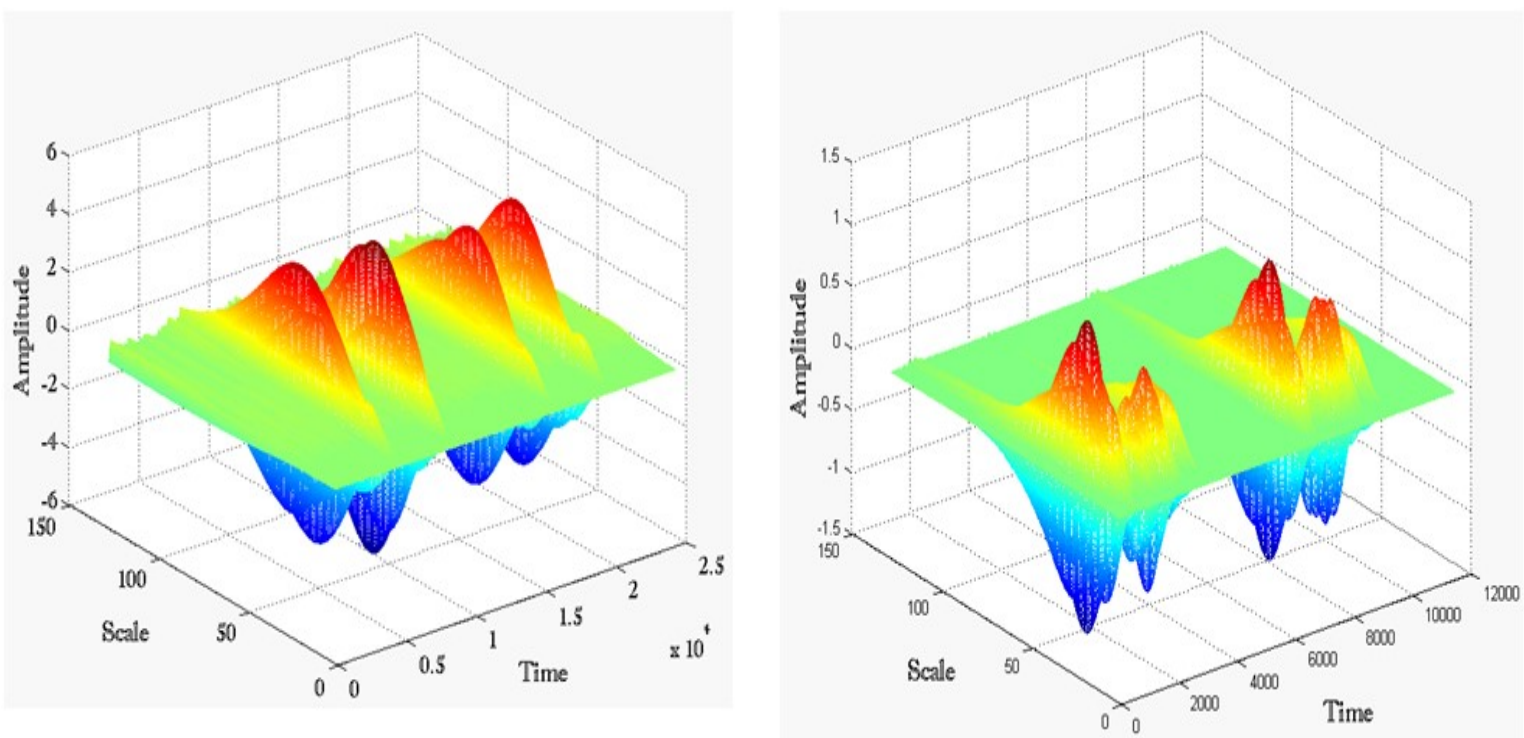

Fig. (6a): Mesh plot of denoised normal PCG acoustic signal. (b) Mesh plot denoised abnormal PCG signal

\section{Feature extraction using DWT}

After PCG acoustic signal denoising and segmentation, it is necessary to extract relevant information or features from the PCG acoustic signal in order to use it in the next stage of PCG acoustic signal analysis and classification. These extracted features have a direct impact on analysis and classification performance. The WT was used to give us information about the temporal extent and frequency spectrum of the PCG acoustic signal. PCG signals were decomposed into subband frequencies by DWT using Db wavelet family of fourth order up to tenth level of decomposition. The approximated and detailed coefficients were computed. Fig. (7) shows the wavelet decomposition levels. The tenth level of decomposition resulted in 11 logarithmically spaced frequency bands with a feature vector dimension of $(44 \times 1)$ since each PCG acoustic signal contains information at different frequency bands.

\section{ANN classifier}

A classifier is a procedure that utilizes different independent variable features as an input and estimates the corresponding output classes to which the independent variables belong. In cardiac sound PCG signals, the features used for classification can be in a form of power, energy, entropy etc. In this work ANN is used for the classification process [34], ANN is a fully connected computational neurons system. Generally, in ANN, the nodes (neurons) are organized into layers. Firstly, an input layer where the input vector is fed in, then, an output layer that generates the output vector, and one or more layers in between called hidden layers [35, 43].

Each layer has computational neurons, which map the input vector into some output class. Furthermore, each neuron receives an input, applies transfer function to it and after that throws the output onto the following layer. In general, the networks are defined as feed forward or feedback networks. Adjusting weights are applied to the signals, flowing from one node to another. These weights, used in the training phase, can classify vectors arbitrarily well; given enough neurons in its hidden layer. 


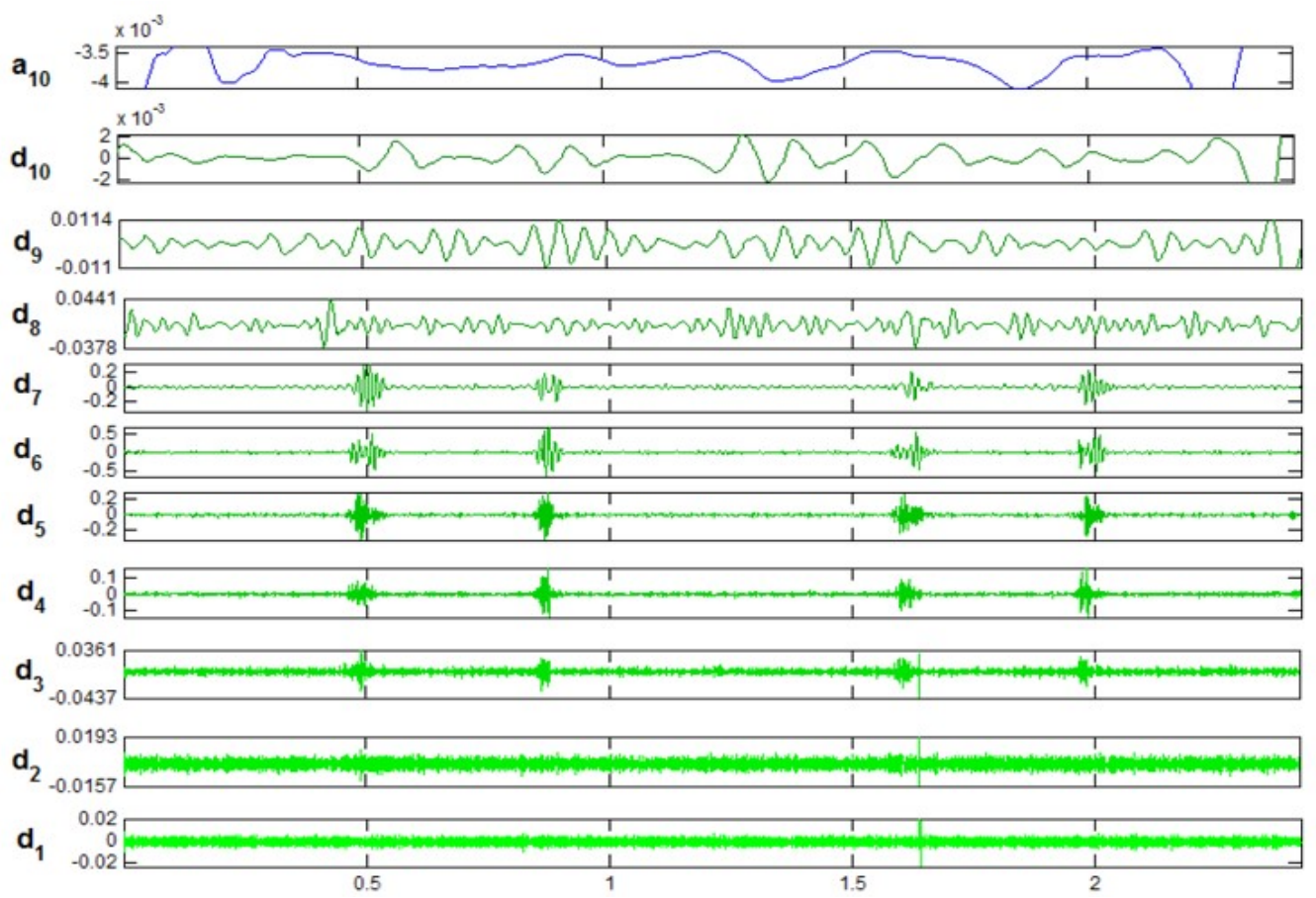

Fig. (7): Wavelet Coefficients for normal sound signal at tenth level of decomposition

The classification process of the neural network starts with sum of all inputs multiplied with corresponding weights, plus bias at the neuron. After the sum is computed, it moves to the transfer function and passes to the next layers to obtain the final output (feed forward) [34]. Training means adapting the weights of the network. Change the weights until the operation gives the desired output.

In the present case, a suitable ANN classifier is designed to identify the PCG acoustic signals. The size of the input layer depends on the dimension of feature vector extracted from the cardiac sound PCG signals, while the size of the output layer depends on the number of the classified categories (normal or abnormal). This neural network is learned, using momentum BP learning method with gradient descent (GD) and tan-sigmoid as a transfer function. The activation output is calculated using: $Y_{i}^{1}=F\left(u_{i}\right)$, where $F\left(u_{i}\right)$ is the transfer function, which may be thought of as providing a nonlinear result for the simulated neuron. The sigmoid function is mostly used to produce the output from each node in the network as follows: $F(u)=\frac{1}{1+e^{-u}}$, Where $u$ is the activation of a neuron, where $u_{i}=\sum_{j=1}^{N_{i}-1} w_{i j}^{1} Y_{j}^{1}+b_{i}^{1}$. Here, $Y_{i}^{1}$ is the activation of the $\mathrm{i}^{\text {th }}$ neuron in the $1^{\text {th }}$ layer; $w_{i j}^{1}$ is the weight of the connection from the $j^{\text {th }}$ neuron in the one to one layer to the $i^{\text {th }}$ neuron in the $1^{\text {th }}$ layer; $b_{i}^{1}$ is the bias connected to the $\mathrm{i}^{\text {th }}$ neuron in the $1^{\text {th }}$ layer; and $\mathrm{N}_{1}-1$ is the number of neurons in the one to one layer.

$Y_{i}^{1}=f\left(\sum_{j=1}^{N_{i}-1} w_{i j}^{1} Y_{j}^{1}+b_{i}^{1}\right)$

To build up a relation between the input and output, the ANN should be adjusted and trained.

\section{Experimental Results and Discussion}

The validation and discussion of the experimental results are presented in this section. We start with the experimental setup used in this work. The experimental results are carried out in MATLAB 2014a software package. A170 PCG acoustic signals were selected from PASCAL CHSC 2011 heart sound dataset $[14,44$, and 45]. The noise in each signal was eliminated using Db10 wavelet with fourth level of decomposition. After signal denoising, signals were separated and segmented 
into main events in the cardiac cycle such as (S1), (S2) and murmurs using calculated envelope from the NASE. For each signal 44DWT based features are extracted establishing a feature vector of size (44x1) for every PCG signal then, fed as an input to the feed forward ANN classifier. The ANN classifier is trained for these extracted features utilizing the ten-fold cross validation (CV) technique [34]. This method has the advantage that it utilizes all the instances in the dataset for training and testing. The ANN performance is assessed utilizing the metrics: sensitivity (Se), specificity (Sp) and accuracy (Ac). These metrics are defines as follows:

$$
\begin{aligned}
& \text { Se }=\frac{\text { True Positive }}{\text { True Positive }+ \text { FalseNegative }} \times 100, \\
& S p=\frac{\text { True Negative }}{\text { True Negative }+ \text { FalsePositive }} \times 100,
\end{aligned}
$$$$
\text { and } A c=\frac{\text { Total no. of correctly signals }}{\text { Total no. of signals }} \times 100
$$

\section{Classification Results}

The extracted (44x1) DWT features vectors for each signal were classified into normal or pathological classes using ANN classifier. Four layered neural networks (input layer, two hidden layers, and output layer) were used. The number of neurons in the $1^{\text {st }}$ hidden layer is 23 neurons, 5 neurons in the $2^{\text {nd }}$ hidden layer and one neuron in the output layer. The training algorithm used to train the proposed network is multi-layer perceptron $\mathrm{BP}$ algorithm with momentum constant equals 0.2 and learning rate equals 0.3 and 4000 epochs. The transfer function used in these hidden layers and the output layer is the sigmoid activation function. In the output layer one neuron is used (0 or 1) stating standard or abnormal class. The classification process was conducted for the extracted features and the results are notable. The ANN classifier achieved $99.89 \%$ Ac with $99.89 \%$ Seand $99.89 \%$ Sp. Table (1) summarizes the used parameters in the system. The classification performance results in this research are found to be better related to (compared with) similar researches using similar classifiers.

Table (2) presents the achieved Ac, Se, and Sp of individual class (standard and abnormal), as well as information about the systems used for different methods.

\begin{tabular}{|c|c|c|c|c|c|c|c|}
\hline \multirow[t]{2}{*}{ Database } & \multicolumn{2}{|c|}{ Preprocessing } & \multirow{2}{*}{$\begin{array}{c}\text { Feature } \\
\text { extraction }\end{array}$} & \multirow[t]{2}{*}{ Classification } & \multicolumn{3}{|c|}{ Performance } \\
\hline & Denoising & Segmentation & & & $\mathrm{Se} \%$ & $\mathrm{Sp} \%$ & $\mathrm{Ac} \%$ \\
\hline $\begin{array}{l}\text { PASCAL } \\
\text { CHSC } \\
20011 \\
170 \text { from } \\
\text { Set A) [14] }\end{array}$ & $\begin{array}{l}\text { Donoho denoising } \\
\text { with Wavelet Family: } \\
\text { Db } 10 \\
\text { Level of } \\
\text { Decomposition: } 4^{\text {th }} \\
\text { Threshold Rule: } \\
\text { Rigrsure } \\
\text { Threshold type: Hard }\end{array}$ & $\begin{array}{lr}8^{\text {th }} & \text { order } \\
\text { Chebyshev } & \text { type } \\
\text { (I) filter ASE } & \end{array}$ & $\begin{array}{l}\text { WT Family: } \\
\text { Db10 } \\
\text { Level of } \\
\text { Decomposition: } \\
10^{\text {th }}\end{array}$ & $\begin{array}{l}\text { ANN } \\
44 \times 23 \times 5 \times 1 \\
\text { BP learning } \\
\text { algorithm with } \\
\text { Momentum } \\
\text { Constant equals } \\
0.2 \\
\text { Learning rate } \\
\text { equals } 0.3 \\
4000 \text { epecho } \\
\text { ten-fold CV }\end{array}$ & 99.89 & 99.89 & 99.89 \\
\hline
\end{tabular}

Table (1): The parameters of and the classification of the proposed approach 
Table (2): Several related feature extraction and classifications methods compared with our proposed methodology

\begin{tabular}{|c|c|c|c|c|c|c|}
\hline \multirow[b]{2}{*}{ Author } & \multirow[b]{2}{*}{ Database } & \multirow[b]{2}{*}{ Features extraction method } & \multirow[b]{2}{*}{ Classifier } & \multicolumn{3}{|c|}{ Performance } \\
\hline & & & & $\begin{array}{l}S p \\
(\%)\end{array}$ & $\begin{array}{l}S e \\
(\%)\end{array}$ & $\operatorname{Acc}(\%)$ \\
\hline \multirow[t]{2}{*}{$\begin{array}{l}\text { C. N. Gupta et al, } \\
\text { (2007) [21] }\end{array}$} & \multirow{2}{*}{$\begin{array}{l}41 \text { volunteer collected } \\
\text { from Singapore general } \\
\text { hospital( } 340 \text { patterns), } \\
\text { it was divided into three } \\
\text { datasets (D1, D2, D3) } \\
\text { each with } 112 \text { patterns } \\
\text { (45 used for the } \\
\text { training, and } 67 \text { patterns } \\
\text { were used for testing }\end{array}$} & \multirow{2}{*}{$\begin{array}{l}\text { DWT detail coefficients at the } \\
\text { second decomposition level was } \\
\text { split into } 32 \text { sub windows with } \\
\text { each window containing } 128 \\
\text { discrete data values }\end{array}$} & GAL & --- & --- & $\begin{array}{l}\text { D1:97.01 } \\
\text { D2: } 8.50 \\
\text { D3:95.55 }\end{array}$ \\
\hline & & & MLP-BP & $\begin{array}{ll}--- \\
\end{array}$ & --- & $\begin{array}{l}\mathrm{D} 1: 97.01 \\
\text { D2:97.01 } \\
\text { D3: } 5.55\end{array}$ \\
\hline $\begin{array}{l}\text { Z. Dokur et al, } \\
(2008)[25]\end{array}$ & Dataset of 14 signals. & $\begin{array}{c}\text { The elements of the feature } \\
\text { vectors are formed by the ten } \\
\text { power values of each sub-band } \\
\text { in the five decomposition levels } \\
\text { of DWT. }\end{array}$ & ANN & $\begin{array}{ll}--- \\
--1\end{array}$ & --- & 95 \\
\hline $\begin{array}{l}\text { S. Ari et al, } \\
(2009)[46]\end{array}$ & $\begin{array}{c}104 \text { signals from } \\
\text { Maulana Azad Medical } \\
\text { Hospital } \\
\end{array}$ & $\begin{array}{l}\text { DWT detail and approximate } \\
\text { coefficients using DB wavelet of } \\
\text { 2nd order. }\end{array}$ & ANN & $\begin{array}{ll}--- \\
-1\end{array}$ & --- & 99.28 \\
\hline $\begin{array}{c}\text { R. Das } \\
(2009)[47]\end{array}$ & 215 signals & $\begin{array}{l}\text { WT detail and approximate } \\
\text { coefficients }\end{array}$ & $\overline{\mathrm{ANN}}$ & 96 & 100 & 97.4 \\
\hline $\begin{array}{l}\text { F. Safara et al, } \\
\quad(2013) \\
{[48]}\end{array}$ & $\begin{array}{c}59 \text { heart sounds } \\
\text { including } 16 \text { normal } \\
\text { and } 43 \text { pathological } \\
\text { hearts sounds }\end{array}$ & $\begin{array}{l}\text { A feature vector was constructed } \\
\text { for each of the PCG recordings } \\
\text { including the relative energy of } \\
\text { the selected nodes using WT. }\end{array}$ & SVM & ---- & --- & 92.1 \\
\hline $\begin{array}{l}\text { M. Singh et al, } \\
\text { (2013) [49] }\end{array}$ & $\begin{array}{l}\text { PASCAL CHSC dataset } \\
\text { (60 signals is used } 30 \\
\text { normal signals and } 30 \\
\text { murmur signals) }\end{array}$ & $\begin{array}{c}\text { Five features: Total power - Q } \\
\text { factor - S1 and S2 durations - } \\
\text { mean }\end{array}$ & NB & 93.33 & 93.33 & 93.33 \\
\hline \multirow{4}{*}{$\begin{array}{l}\text { E. Ferreira et al, } \\
\text { (2013) [50] }\end{array}$} & \multirow{4}{*}{$\begin{array}{c}\text { PASCAL CHSC dataset } \\
\text { (312 signals) }\end{array}$} & \multirow{4}{*}{$\begin{array}{l}\text { Six features have been extracted } \\
\text { based on the distance between } \\
\text { S1 and S2 and the linearity of } \\
\text { the segments S1 and S2 using } \\
\text { the SAX-based multi-resolution } \\
\text { Motif Discovery approach }\end{array}$} & $\mathrm{DT}: \mathrm{J} 48$ & \multirow[t]{4}{*}{$\overline{---}$} & \multirow[t]{4}{*}{$\overline{---}$} & 70 \\
\hline & & & LR & & & 65 \\
\hline & & & $\mathrm{RdF}$ & & & 72.76 \\
\hline & & & $\mathrm{RtF}$ & & & 71.4 \\
\hline $\begin{array}{l}\text { N. R . Sujit et al, } \\
\quad(2016)[51]\end{array}$ & $\begin{array}{l}\text { PASCAL CHSC dataset } \\
266 \text { signals is used ( } 200 \\
\text { normal and } 66 \\
\text { abnormal signals) }\end{array}$ & $\begin{array}{l}\text { Features by different analysis } \\
\text { domains: } \\
\text { 1-Distance between the split } \\
\text { sounds S1 and S2.Systolic } \\
\text { period of heart sound. } \\
\text { 2-Frequency domain features } \\
\text { were extracted by applying FFT. } \\
\text { 3-Features were also extracted } \\
\text { after wavelet decomposition. }\end{array}$ & $\mathrm{RT}$ & 86.81 & 84.92 & 83.33 \\
\hline $\begin{array}{l}\text { Z. Tong et al, } \\
\text { (2015) [52] }\end{array}$ & $\begin{array}{l}\text { PASCAL CHSC dataset } \\
\text { (35 records of normal } \\
\text { and } 45 \text { records } \\
\text { abnormal PCG) } \\
\end{array}$ & $\begin{array}{c}\text { WT based de-noising, energy- } \\
\text { based segmentation HHT based } \\
\text { features }\end{array}$ & SVM & 81.8 & 100 & 90.5 \\
\hline $\begin{array}{l}\text { Our proposed } \\
\text { System }\end{array}$ & $\begin{array}{c}\text { PASCAL CHSC dataset } \\
\text { (170 signals is used } 34 \\
\text { are normal signals and } \\
136 \text { are abnormal } \\
\text { signals) } \\
\end{array}$ & $\begin{array}{l}\text { Energy, Variance, Waveform } \\
\text { Length, Entropy after DWT } \\
\text { decomposition. }\end{array}$ & $\overline{\mathrm{ANN}}$ & 99.89 & 99.89 & 99.89 \\
\hline
\end{tabular}




\begin{tabular}{|c|c|c|c|c|c|c|}
\hline $\begin{array}{l}\text { D. Kucharski et } \\
\text { al, } \\
\text { (2017) [53] }\end{array}$ & $\begin{array}{c}\text { PASCAL CHSC } \\
\text { Dataset } \\
\text { Train Set : } 984 \text { Sample } \\
\text { Validation Set : } 121 \\
\text { Sample } \\
\text { Test Set }=123 \text { Sample } \\
\end{array}$ & $\begin{array}{l}\text { T-F analysis (Spectrogram) for } \\
\text { signal sections with an amount } \\
\text { of normal and abnormal signals }\end{array}$ & $\mathrm{CNN}$ & 91.6 & 99.1 & --- \\
\hline $\begin{array}{l}\text { V. Nivitha et al, } \\
\text { (2016) [54] }\end{array}$ & $\begin{array}{c}\text { PASCAL CHSC } \\
\text { Dataset } \\
\text { Total records }=832 \\
\text { Test records }=50\end{array}$ & EWT + SE envelope & $\begin{array}{l}\text { Based on } \\
\text { EWT } \\
\text { and EMD }\end{array}$ & $\begin{array}{l}---- \\
\end{array}$ & - & 95 \\
\hline \multirow[t]{2}{*}{$\begin{array}{l}\text { W. Zhang et al, } \\
\text { (2017) [55] }\end{array}$} & $\begin{array}{l}\text { PASCAL CHSC } \\
\text { Dataset-A }\end{array}$ & \multirow{2}{*}{$\begin{array}{c}\text { The SE envelope }+ \\
\text { Spectrograms + bilinear } \\
\text { interpolation for scaling + partial } \\
\text { least squares regression for } \\
\text { dimension reduction }\end{array}$} & \multirow[t]{2}{*}{ SVM } & \multirow[t]{2}{*}{$\begin{array}{l}---- \\
\end{array}$} & \multirow[t]{2}{*}{$\begin{array}{l}--- \\
\end{array}$} & $\begin{array}{c}\text { Total } \\
\text { Precision } \\
\text { Dataset } \\
\mathrm{A}=2.89 \\
\end{array}$ \\
\hline & Dataset-B & & & & & $\begin{array}{c}\text { Dataset } \\
\mathrm{B}=1.75\end{array}$ \\
\hline \multirow{6}{*}{$\begin{array}{l}\text { S. W. Deng et al, } \\
\text { (2016) [30] }\end{array}$} & \multirow{3}{*}{$\begin{array}{l}\text { PASCAL CHSC } \\
\text { Dataset-A }\end{array}$} & \multirow{6}{*}{$\begin{array}{l}\text { Fusion of autocorrelation and the } \\
\text { DWT approximation and details }\end{array}$} & SVM-A & & & \\
\hline & & & SVM-AD & 64 & 100 & $\mathrm{P}=64$ \\
\hline & & & SVM-DM & 58 & 100 & $\mathrm{P}=94$ \\
\hline & \multirow[t]{3}{*}{ Dataset-B } & & SVM-A & & & \\
\hline & & & SVM-AD & 95 & 34 & $\mathrm{P}=79$ \\
\hline & & & SVM-DM & 90 & 39 & $\mathrm{P}=76$ \\
\hline $\begin{array}{l}\text { J. Pedrosa, et al, } \\
\text { (2014) [56] }\end{array}$ & $\begin{array}{c}\text { PASCAL CHSC } \\
\text { Dataset } \\
111 \text { signals of the } \\
\text { database is considered } \\
\end{array}$ & $\begin{array}{c}250 \text { features were extracted } \\
\text { from different analysis domains: } \\
\text { Time domain, T-F analysis, 3- } \\
\text { DWT and CWT. }\end{array}$ & KNN & 79.40 & 52.38 & 79.2 \\
\hline \multirow[t]{3}{*}{$\begin{array}{l}\text { M. Hamidi, et al, } \\
\text { (2018) [57] }\end{array}$} & $\begin{array}{l}\text { PASCAL CHSC } \\
\text { Dataset-A } \\
\end{array}$ & \multirow{3}{*}{$\begin{array}{l}\text { Curve fitting and MFCC fused } \\
\text { with fractal features Stacking } \\
\text { used to extract the features. }\end{array}$} & \multirow[t]{3}{*}{$\begin{array}{c}\text { KNN } \\
\text { with ED }\end{array}$} & \multirow[t]{3}{*}{$\begin{array}{l}---- \\
\end{array}$} & \multirow[t]{3}{*}{----} & $A=92$ \\
\hline & $\begin{array}{l}\text { PASCAL CHSC } \\
\text { Dataset-B } \\
\end{array}$ & & & & & $\mathrm{B}=81$ \\
\hline & PhysioNet Dataset-C & & & & & $\mathrm{C}=98$ \\
\hline \multirow[t]{3}{*}{$\begin{array}{c}\text { W. Zhang } \\
\text { Et al, (2017) [58] }\end{array}$} & $\begin{array}{l}\text { PASCAL CHSC } \\
\text { Dataset } \\
\text { Dataset-A } \\
\end{array}$ & \multirow[t]{3}{*}{$\begin{array}{l}\text { Scaled spectrograms + tensor } \\
\text { decomposition method }\end{array}$} & \multirow[t]{3}{*}{ SVM } & \multirow[t]{3}{*}{$\begin{array}{l}---- \\
\end{array}$} & \multirow[t]{3}{*}{$-\overline{---}$} & $\mathrm{pt}=2.91$ \\
\hline & $\begin{array}{l}\text { PASCAL CHSC } \\
\text { Dataset-B } \\
\end{array}$ & & & & & $\mathrm{pt}=1.68$ \\
\hline & PhysioNet Dataset-C & & & & & $\begin{array}{c}\text { Overall } \\
\text { score } \\
90 \\
\end{array}$ \\
\hline $\begin{array}{l}\text { H. L Her et al, } \\
\text { (2016)[59] }\end{array}$ & $\begin{array}{l}\text { PhysioNet/CinC } \\
\text { Challenge }\end{array}$ & $\begin{array}{l}\text { Springer's modified version of } \\
\text { Schmidt's method for } \\
\text { segmentation and fast-Fourier } \\
\text { Transform (FFT) for feature } \\
\text { extraction } \\
\end{array}$ & ANN & 86.9 & 84.4 & 86.5 \\
\hline $\begin{array}{l}\text { P. Langley et al, } \\
(2017)[58]\end{array}$ & $\begin{array}{l}\text { PhysioNet-CinC } \\
\text { Challenge }\end{array}$ & $\begin{array}{c}\text { Combination of FFT and WT } \\
\text { entropy }\end{array}$ & $\overline{\mathrm{DT}}$ & 80 & 77 & 79 \\
\hline $\begin{array}{l}\text { M. Zabihi et al, } \\
\text { (2016) [61] }\end{array}$ & $\begin{array}{l}\text { PhysioNet-CinC } \\
\text { Challenge }\end{array}$ & $\begin{array}{l}\text { With no need to segmentation, } \\
\text { features are extracted from time, } \\
\text { frequency, and T-F domains }\end{array}$ & $\overline{\mathrm{ANN}}$ & 88.76 & 94.23 & 91.50 \\
\hline \multirow[t]{2}{*}{$\begin{array}{l}\text { M. N., Homsi et } \\
\text { al, (2017) [62] }\end{array}$} & $\begin{array}{l}\text { PhysioNet-CinC } \\
\text { Challenge } \\
\text { Standard Signal }\end{array}$ & \multirow[t]{2}{*}{$\begin{array}{l}\text { Features extracted based on } \\
\text { time, frequency, wavelet and } \\
\text { statistical domains. }\end{array}$} & \multirow{2}{*}{$\begin{array}{l}\text { Ensemble } \\
\text { classificati } \\
\text { on based } \\
\text { on RF, LB } \\
\text { and CSC }\end{array}$} & ---- & -- & 96.30 \\
\hline & Outliers Signal & & & ---- & -- & 90.18 \\
\hline
\end{tabular}


GAL: Grow and Learn, MLP-BP: Multilayer Perceptron-Back propagation, NB: naive Bayes, DT.J48: Decision tree J48, RdF: Random Forest, RtF: Rotation Forest:, LB: Logical Boost, DT: Decision tree, KNN: k-nearest neighbors, SVM-AD: Support vector machine based on approximation and details features, SVM-DM: Support vector machine based on fused features EWT: Empirical wavelet transform, CNN: convolution neural Network, HHT: Hilbert-Huang Transformation, RT: Regression Tree, EMD: early-diastolic murmurs, CSC: Cost-Sensitive Classifier, SE: Shannon energy

\section{Discussion}

The objective of this work is to automatically differentiate between the pathological and standard PCG acoustic signals. Thus, the results of this differentiation provide a preliminary diagnosis of cardiac diseases and it can help to decide whether it is necessary to conduct further examination. Moreover, the proposed intelligent approach (ANN with DWT) is evaluated on PASCAL CHSC dataset and compared with other methodologies by others. The results are demonstrated in Table (2),they obviously demonstrate that the developed approach is competitive and has a very good $\mathrm{Ac}, \mathrm{Sp}$ and $\mathrm{Se}$ compared to various models reported by other researchers.

A direct comparison of the obtained results with the previous works by other researchers in PCG acoustic signals analysis was a difficult task due to the PCG datasets variety, wavelets families, levels of decomposition and the classifiers used. However, a general comparison with the previous related researches is demonstrated in this section (Table 2). The information about datasets, feature extraction, classifiers performance and ML algorithms are demonstrated in Table (2).

The list of researches listed in Table (2) have utilized time, frequency, T-F domains and WT to capture cardiac sound PCG signal features for investigation and classification. The majority of these researches used nonlinear classifiers; such as ANN and SVM to classify the pathological and standard PCG signals.

As can be found in Table (2), the integration of ANN with the WT and also SVM with WT have the best average classification accuracy (e.g. R. Das et al. [47] obtained of $97.4 \%$ overall accuracy using ANN and WT, F. Safara et al. [48] achieved an overall accuracy of 92.1 based on the combination of SVM and WT). By comparing the ANN with the SVM classifier it can be concluded that the ANN classifier should be further utilized as the fundamental classification system due to its high performance in terms of classification accuracy. Additionally, in the view of the literature and results of classification for standard and pathological heart states displayed in Table (2), it can be concluded that choosing a particular filtration type, feature extraction method and classifiers may not provide more accurate results for all the classification cases. Thus a development of an efficient model and adjustment of its parameters are necessary.

To have a fair comparison, we compared the results obtained from our developed approach of the methods conducted on the same dataset (PASCAL CHSC dataset).

The evaluation graphs of the Se, Sp and the Ac graph are shown in Fig.(11). Based on the experimental results, our proposed method gives better results compared with other classifiers (ANN and SVM) (conducted on PSCAL CHSC dataset).

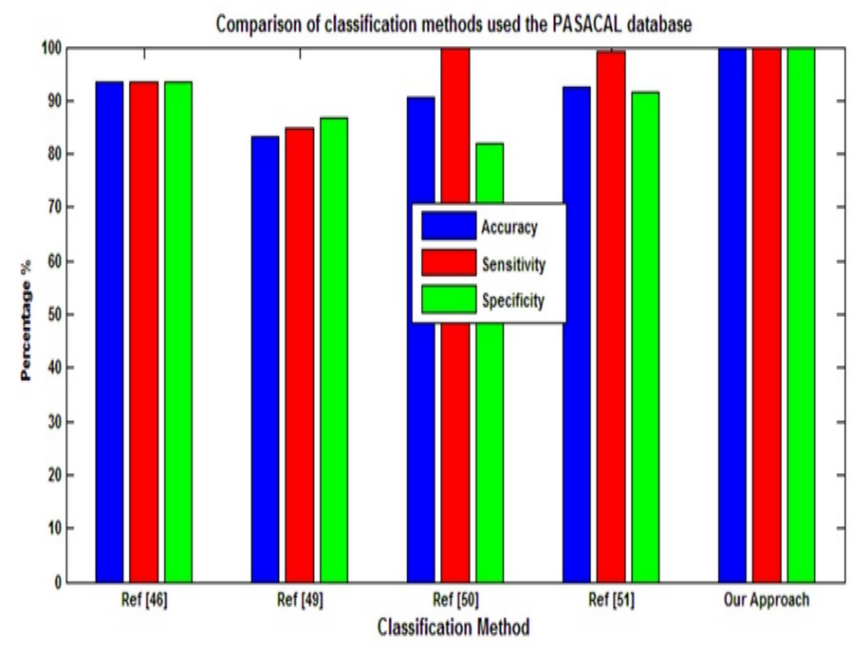

Fig. (11): Comparison of the accuracy of our proposed model with other researchers for the same database (PASCAI CHSC)

From the results in Table (2) and Fig, (11), it was observed that the proposed model achieves better Ac, Se and Spas compared to various models reported by other researchers [50-56].

Evaluation of results demonstrates the potentiality of the proposed PCG acoustic signal classification method for automatically differentiating between pathological and normal PCG signal. 
This approach is a promising candidate for clinical applications and can be used in routine diagnostic protocols in cardiac diagnostic centers in the future. The major contribution of the present work considering other existing works is that the proposed approach uses WT to obtain an effective Denoising and extensible feature extraction methods combined with BP-ANN for achieving the highest accuracy of $99.89 \%$.

The limitation of this work is that it requires more training whenever there is an increase in cardiac acoustic signal database. Future research can address the extension of the developed technique for processing more acoustic cardiac signals, regarding the diastolic and systolic murmur classifications and the applications; such as valvular split analysis, cardiac stress test, pulmonary artery pressure analysis, systolic pressure estimation, noninvasive blood pressure estimation, and PCG based biometric systems.

However, the analyses and comparative studies of algorithms in the literature have revealed the shortage of extensive and open datasets of cardiac sound signal recordings. The Physio-netComputing in Cardiology (CinC) Challenge 2016 [44] considered this matter by gathering the largest public cardiac sound database, assembled from both pathological and standard ones with different conditions; such as heart valve disease (HVD) and coronary artery disease (CAD). M. Homsi et al. [61] developed an ensemble classification method based on Random forest (RF), Logical Boost (LB) and Cost-sensitive classifiers to achieve $96 \%$ overall accuracy using the Physio net CinC database.

This work can be further improved by considering the diastolic and systolic murmur detection and cardiac disease classification (for example, mitral regurgitation (MR), aortic stenosis (AS), mitral stenosis (MS), etc.). To achieve this expectancy, one must enlarge the database, eliminate or reduce noise in signals and try different feature extraction methods (e.g. T-F and T-S based methods). Essential steps include the hybrid classifiers and deep learning should be tried and considered for suitable signal segmentation and classification. Achieving this goal will address the limitations of existing approaches (Such as: poor performance with huge number of data records).

\section{Conclusion}

This paper proposed an intelligent approach for addressing the analysis and classification of PCG acoustic signal analysis based on DWT features and ANN classifiers. Based on the proposed approach, we have classified the PASCAL CHSC heart sound dataset into abnormal and normal classes. We used 121 out of 170 signals (set A) and the ten-fold CV method to develop and train the proposed approach. Therefore, 44 features are extracted from each signal using $\mathrm{Db}$ wavelet family of fourth order, with tenth level of decomposition used as a feature input vector for training the feed-forward back-propagation ANN to identify the PCG signals. We have accomplished overalls accuracy of $99.89 \%$ using feed forward ANN; which proves the enormous efficiency of the proposed approach (compared to other researchers).It is expected now that future research in this trend will conduct sufficient tests on a larger number of additional samples. Moreover, a larger number of classes (e.g. types of pathological cardiac sound) should be presented for further examination of the final system capabilities. Also, hybrid approaches and deep learning techniques need to be considered for feature extraction and classification.

\section{References}

1-Roth G A, Johnson C, Abajobir A, Abd-Allah F, Abera S F, Abyu G, Ahmed M, Aksut B, Alam T, AlamK,Alla F (2017) Global, regional, and national burden of cardiovascular diseases for 10 causes, 1990 to 2015. J Am Coll Cardiol70: 125.doi:10.1016/j.jacc.2017.0w4.052.

2-Cardiovascular diseases-Facts sheet:http://www.who.int/mediacentre/factsheets/fs31 7/en/ (accessed20 Feb. 2018).

3-Laennec RTH (1819) De l'auscultation mediate (On Mediate Auscultation): outraité du diagnostic des maladies des poumons et du coeur. Vol.2, Translated from the French edition by John Forbes. New York: Samuel Wood and Sons, (1935).

4-Karnath B, Thornton W (2002) Auscultation of the heart. Hospital Physician. 38: 39-45.

5-Tavel ME (1996) Cardiac auscultation. Circulation, 93: 12501253.doi:10.1161/CIRCULATIONAHA.105.591149

6-Mangione S, Nieman L Z (1997) Cardiac auscultatory skills of internal medicine and family practice trainees: a comparison of diagnostic proficiency. Jama. 278: 717-722. doi:10.1001/jama.278.9.717

7-Balasubramaniam D,Nedumaran D (2010) Efficient computation of phonocardiographic signal analysis in 
digital signal processor based system. International journal of computer theory and Engineering, 2: 660664, doi:10.7763/IJCTE.2010.V2.219

8-Abbas A K, Bassam R(2009) Phonocardiography Signal Processing, Synthesis Lectures on Biomedical Engineering Vol. 4, No. 1, Pages 1194,doi:10.2200/S00187ED1V01Y200904BME031

9- Choudhary T, Sharma LN, Bhuyan M K (2018) Heart sound extraction from sternal seismo cardiographicsignal, IEEE Signal Proc Let25: 482486doi:10.1109/LSP.2018.2801341

10-Huseyin C,Yigit $\mathrm{T}(2018)$ Artificial intelligence applications on classification of heart sounds, In nature-inspired intelligent techniques for solving biomedical Engineering Problems, pp. 146-183. IGI Global; doi: 10.4018/978-1-5225-4769-3.ch007

11-Hamidi M, Ghassemian H, Imani M (2018) Classification of heart sound signal using curve fitting and fractal dimension. Biomed Signal Proces 39: 351-359, doi:10.1016/j.bspc.2017.08.002

12-Kumar AK, Saha G(2018) Improved computerized cardiac auscultation by discarding artifact contaminated PCG signal sub-sequence. Biomed Signal Proces 41: 48-62. doi:10.1016/j.bspc.2017.11.001

13-Nabih-Ali M, El-Dahshan E A, Yahia A S (2017) A review of intelligent systems for heart sound signal analysis. J Medi Eng Technol 41: 553563,doi:10.1080/03091902.2017.1382584

14-Bentley P, Nordehn G, Coimbra M, Mannor S, Getz R (2011) The PASCAL classifying heart sounds challenge $2011 \quad$ (CHSC2011) (www.peterjbentley.com/heartchallenge/index.html)Accessed 10 April 2016.

15-Tinati M A, Bouzerdoum A, Mazumdar J(1996) Modified adaptive line enhancement filter and its application to heart sound noise cancellation, in: Proceeding of the International Symposium on Signal Processing and its Applications, pp815-818.

16-Charleston S, Azimi-Sadjadi M R(1996) Reduced order Kalman filtering for the enhancement of respiratory sounds. IEEE T Bio-Med Eng, 43: 421424. doi:10.1109/10.486262

17-Hadjileontiadis L J,Panas SM(1998) A waveletbased reduction of heart sound noise from lung sounds. Int J Med Inform52: 183-190. doi:10.1016/S1386-5056(98)00137-3

18-Messer SR, Agzarian J, Abbott D(2001) Optimal wavelet denoising for phonocardiograms. MICROELECTR J 32: 931-941.doi:10.1016/S00262692(01)00095-7

19-El-DahshanEA, (2011) Genetic algorithm and wavelet hybrid scheme for ECG signal denoising, Telecommun Syst46: 209215.doi:10.1007/s11235-010-9286-2

20-Flores-Tapia D, Moussavi ZM, Thomas G, (2007) Heart sound cancellation based on multiscale products and linear prediction. IEEE T Bio-Med Eng 54: 234-243,doi:10.1109/TBME.2006.886935

21-Gupta C N, Palaniappan R, Swaminathan S, Krishnan SM (2007) Neural network classification of homomorphic segmented heart sounds. Appl SoftComput7: 286297.doi:10.1016/j.asoc.2005.06.006

22-UğuzH, ArslanA ,Saraçoğlu R, Türkoğlu İ(2008) Detection of heart valve diseases by using fuzzy discrete hidden Markov model. Expert SystAppl 34: 2799-2811, doi:10.1016/j.eswa.2007.05.004

23-Eslamizadeh G., Gholamhossein, Barati R., (2017) Heart murmur detection based on wavelet transformation and a synergy between artificial neural network and modified neighbor annealing methods, Arti fIntell Med 78: 23-40, doi:10.1016/j.artmed.2017.05.005

24-Huiying L, Sakari L, IiroH(1997) A heart sound segmentation algorithm using wavelet decomposition and reconstruction. In Engineering in Medicine and Biology Society, In: Proceedings of the 19th Annual International Conference of the IEEE (Vol. 4) 16301633.

25-Dokur Z, Ölmez T (2008)Heart sound classification using wavelet transform and incremental selforganizing map. Digit Signal Process 18: 951-959. doi:10.1016/j.dsp.2008.06.001

26-Daubechies I (1992) Ten lectures on wavelets. Society for industrial and applied mathematics (Siam). doi:10.1137/1.9781611970104.fm

27-Kao WC, Wei CC (2011) Automatic phonocardiograph signal analysis for detecting heart valve disorders. Expert SystAppl 38: 6458-6468. doi:10.1016/j.eswa.2010.11.100

28-Gavrovska A, Bogdanović V, Reljin I, Reljin B (2014) Automatic heart sound detection in pediatric patients without electrocardiogram reference via pseudo-affine Wigner-Ville distribution and Haar wavelet lifting. Comput Meth Prog Bio 113: 515528. doi:10.1016/j.cmpb.2013.11.018

29-Patidar S, Pachori R B, Garg N, (2015) Automatic diagnosis of septal defects based on tunable-Q wavelet transform of cardiac sound signals. Expert Syst Appl 42: 33153326.doi:10.1016/j.eswa.2014.11.046

30-Deng SW, Han JQ(2016) Towards heart sound classification without segmentation via autocorrelation feature and diffusion maps, Future Gener Comp Sy 60: 13-21, doi:10.1016/j.future.2016.01.010

31-Wu CH, Lo C W, Wang J F (1995) Computer-aided analysis and classification of heart sounds based on neural networks and time analysis. In: proceeding of in acoustics, speech, and signal processing, ICASSP95International Conference on (Vol. 5) IEEE pp. 3455-3458).

32-Wu C H (1997) on the analysis and classification of heart sounds based on segmental Bayesian networks 
and time analysis, Journal of the Chinese Institute of Electrical Engineering: Transactions of the Chinese Institute of Engineers, 4: 343-350.

33-White PR, Collis WB, Salmon AP(1996) Analyzing heart murmurs using time-frequency methods. In Time-Frequency and Time-Scale Analysis, Proceedings of the IEEE-SP International Symposium on IEEE, pp. 385-388.

34-Haykin S O(2009) Neural networks and learning machines. Vol. 3. Upper Saddle River, NJ, USA: Pearson,

35-Fahad H M, Khan G, Usman M, Saba T, Rehman A, Iqbal S(2018) Microscopic abnormality classification of cardiac murmurs using ANFIS and HMM. Micros res techniqdoi:10.1002/jemt.22998.

36-Mallat S (1999) A wavelet tour of signal processing. Academic press, doi:10.1162/comj.2007.31.3.83

37-Mallat, Stephane G(1989) A theory for multiresolution signal decomposition: the wavelet representation, IEEE T Pattern Anal 11: 674693.doi:10.1109/34.192463

38-Deng, SW, Han, JQ (2018) Adaptive overlappinggroup sparse denoising for heart sound signals, Biomed Signal Proces40: 49-57, doi:10.1016/j.bspc.2017.08.027

39-Nabih-Ali M, El-Dahshan EA, Yahia AS(2017) Heart Diseases Diagnosis Using Intelligent Algorithm Based on PCG Signal Analysis, Circuits and Systems 8: 184.doi:10.4236/cs.2017.87012

40-Donoho D L(1995) De-noising by softthresholding. IEEE $\mathrm{T}$ inform theory, 41: 61362.doi:10.1109/18.382009

41-Moukadem, Dieterlen A, Hueber N, and Brandt C (2013) A robust heart sounds segmentation module based on S-transform. Biomed Signal Proces8: 273281. doi:10.1016/j.bspc.2012.11.008

42-Kudriavtsev V, Polyshchuk V, Roy DL(2007) Heart energy signature spectrogram for cardiovascular diagnosis, Biomedical engineering online 6:16-11622 pages.doi:10.1186/1475-925X-6-16.

43-DeGroff CG, Bhatikar S, Hertzberg J, Shandas R, Valdes-Cruz L, Mahajan R L(2001) Artificial neural network-based method of screening heart murmurs in children. Circulation, 103: 2711-2716, doi:10.1161/01.CIR.103.22.2711.

44-Liu C, Springer D, Li Q, Moody B, Juan RA, Chorro F J, Castells F, Roig J M, Silva I, Johnson A E, Syed Z (2016) An open access database for the evaluation of heart sound algorithms; Physiol Meas 37: 2181-2213.doi:10.1088/0967-3334/37/12/2181

45-Clifford GD, Liu C, Moody B, Springer D, Silva I, Li Q, Mark R G(2016) Classification of normal/abnormal heart sound recordings: the PhysioNet/ Computing in Cardiology Challenge 2016. In Computing in Cardiology Conference (CinC) IEEE, pp. 609612.doi:10.23919/CIC.2016.7868816
46-Ari S,Saha G(2009) In search of an optimization technique for artificial neural network to classify abnormal heart sounds. Appl Soft Comput 9: 330340.doi:10.1016/j.asoc.2008.04.010

47-Das R, Turkoglu I, and Sengur A (2009) Diagnosis of valvular heart disease through neural networks ensembles. Computer methods and programs in biomedicine, 93:

$185-$ 191.doi:10.1016/j.cmpb.2008.09.005

48-Safara F, Doraisamy S, Azman A, Jantan A, Ramaiah ARA(2013) Multi-level basis selection of wavelet packet decomposition tree for heart sound classification. Comput Biol Med, 43:14071414.doi:10.1016/j.compbiomed.2013.06.016

49-Singh M, Cheema A (2013) Heart sounds classification using feature extraction of phonocardiography signal. Int J Comput Appl, 77(4)doi:10.5120/13381-1001

50-Gomes EF, Jorge AM, Azevedo P J (2013) Classifying heart sounds using multiresolution time series motifs: an exploratory study. In Proceedings of the International $\mathrm{C}^{*}$ Conference on Computer Science and Software Engineering, ACM., pp. 23-30, doi:10.1145/2494444.2494458

51-Sujit NR, Kumar CS, Rajesh C B (2016). Improving the performance of cardiac abnormality detection from PCG signal. In AIP Conference Proceedings (Vol. 1715, No. 1, p. 020053).doi:10.1063/1.4942735

52-Tong Z (2015) An integrated framework for cardiac sounds diagnosis. Master's Theses. 671. http://scholarworks.wmich.edu/masters theses/671. (Accessed 20 Feb. 2018).

53-Kucharski D, Grochala D, Kajor M., Kańtoch E ( 2017) A Deep Learning Approach for Valve Defect Recognition in Heart Acoustic Signal. In International Conference on Information Systems Architecture and Technology (pp. 3-14). Springer, Cham.doi:10.1007/978-3-319-67220-5 1

54-Varghees V N, Ramachandran K I (2017) Effective Heart Sound Segmentation and Murmur Classification Using Empirical Wavelet Transform and Instantaneous Phase for Electronic Stethoscope, IEEE Sens J 17.12: 38613872.doi:10.1109/JSEN.2017.2694970

55-Zhang W, Han J, Deng S(2017) Heart sound classification based on scaled spectrogram and partial least squares regression, Biomed Signal Proces32: 20-28, doi:10.1016/j.bspc.2016.10.004

56-Pedrosa J, Castro A, Vinhoza T T (2014) Automatic heart sound segmentation and murmur detection in pediatric phonocardiograms. In Engineering in Medicine and Biology Society (EMBC), 36th Annual International Conference of the IEEE, pp. 22942297).doi:10.1109/EMBC.2014.6944078

57-Hamidi M, Ghassemian H, Imani M (2018) Classification of heart sound signal using curve 
fitting and fractal dimension, Biomed Signal Proces39: 351-359.doi:10.1016/j.bspc.2017.08.002

58-Zhang W, Han J, Deng S (2017) Heart sound classification based on scaled spectrogram and tensor decomposition, Expert Syst Appl 84: 220231.doi:10.1016/j.eswa.2017.05.014

59-Her HL,Chiu HW (2016) Using time-frequency features to recognize abnormal heart sounds. In Computing in Cardiology Conference (CinC) IEEE, (pp. 1145-1147). doi:10.22489/CinC.2016.327-210

60-Langley P, Murray A (2017) Heart sound classification from unsegmented phonocardiograms. Physiol Meas, 38:1658-11658-19 pages), doi:10.1088/1361-6579/aa724c

61-Zabihi M, Rad AB, Kiranyaz S, Gabbou j M, Katsaggelos $\mathrm{AK}(2016)$ Heart sound anomaly and quality detection using ensemble of neural networks without segmentation. In Computing in Cardiology Conference (CinC), IEEE (pp. 613616).doi:10.23919/CIC.2016.7868817

62-Homsi M N, Warrick P (2017) Ensemble methods with outliers for phonocardiogram classification. Physiol Meas 38:1631-1 163112.doi:10.1088/1361-6579/aa7982 